
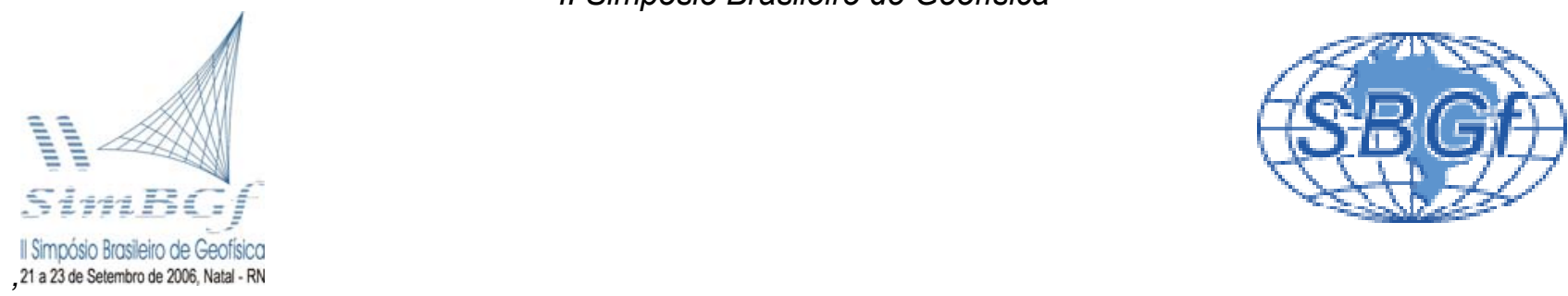

\title{
Sinais Térmicos em subsolo do efeito Estufa no Estado de São Paulo
}

Elias da Conceição e Valiya M. Hamza, OBSERVATÓRIO NACIONAL - ON/MCT, Rio de Janeiro.

Copyright 2006, SBGf - Sociedade Brasileira de Geofísica

Este texto foi preparado para a apresentação no II Simpósio de Geofísica da Sociedade Brasileira de Geofísica, Natal, 21-23 de setembro de 2006. Seu conteúdo foi revisado pela Comisso Tecno-cientifica do I SR SBGf, mas não necessariamen foi revisado pela Comissao Tecno-cientifica do I SR-SBG, mas nao necessaniamente parcial deste material para propósitos comerciais sem prévia autorização da SBGf.

\section{Resumo}

Os resultados de perfilagens geotérmicas realizadas em 15 localidades no Estado de São Paulo têm sido empregados para mapeamento dos sinais térmicos do efeito estufa na região Sudeste. Os mapas revelam que o evento de aquecimento é relativamente mais intenso na região oeste comparada com a região leste do estado de São Paulo. De modo geral, os resultados obtidos indicam que aquecimento climático ocorreu em todas as localidades estudadas. As magnitudes da mudança estão na faixa de $0,2^{\circ} \mathrm{C}$ a $3,8^{\circ} \mathrm{C}$ e as variações climáticas tiveram início no começo do século 19. Há indícios de que as magnitudes das perturbações climáticas são menores na área costeira e maiores na região oeste. É possível que esta tendência é relacionada com a influencia do mar e as características na cobertura vegetal.

\section{Introdução}

Há indícios de que o clima da Terra sofreu mudanças significativas desde a sua formação como um planeta. Os processos internos e externos da Terra contribuíram para mudanças climáticas durante os tempos geológicos. Contudo, a grande parte das mudanças climáticas recentes é induzida pelas atividades solares (Hansen and Lebedeff, 1987). Como exemplo, vimos o surgimento de fenômenos tais como o El Niño e o processo de aquecimento global (conhecido como 'Efeito Estufa'). A reconstrução da história climática anterior ao período de dados instrumentais (cerca de dois séculos) é geralmente efetuada com base em métodos indiretos. A intensidade, a duração e a velocidade com que estas mudanças se deram no passado, bem como suas causas, ainda não são bem conhecidas.

A distribuição de temperaturas em profundidades relativamente pequenas é afetada tanto pelo regime térmico como também pelo fluxo de calor proveniente do interior da Terra. A parcela do calor solar retida na superfície é cerca de duas ordens de grandeza maior do que a do fluxo geotérmico. Conseqüentemente, as variações de temperatura que ocorrem na superfície afetam as camadas do subsolo. A amplitude da perturbação decresce com a profundidade, mas a velocidade da propagação depende da difusividade térmica do solo. Como resultado, os sinais térmicos das mudanças paleoclimáticas encontram-se no campo geotérmico atual das camadas próximas à superfície. O regime térmico em subsuperfície apresenta tipicamente uma zona rasa onde predominam os efeitos de oscilações térmicas de curto período, tais como as diárias e as sazonais. Em profundidades intermediárias, são encontradas perturbações oriundas de variações climáticas. Abaixo disso predomina o efeito do fluxo de calor terrestre.

Este método tem sido amplamente empregado nos estudos paleoclimáticos em diversas partes do mundo (Beck, 1982, Lachenbruch e Marshall, 1986, entre outros). No continente Sul Americano, os estudos pioneiros foram efetuados por Hamza (1991, 1998) através da análise de perfis geotérmicos. Cavalcanti e Hamza (2001) e Cavalcanti (2003) e apresentaram resultados de avaliação das mudanças climáticas nas regiões sudeste e nordeste. Cerrone e Hamza (2003) apresentaram mapa de variações climáticas ocorridas no Estado de Rio de Janeiro.

No presente trabalho procura-se mostrar a natureza das mudanças climáticas ocorridas no último século no Estado de São Paulo, com base em análise de dados de perfilagens térmicas. Utilizamos registros de 15 poços localizados principalmente na região leste.

\section{Metodologia}

O método geotérmico se baseia no equilíbrio térmico entre a temperatura na superfície do planeta e a temperatura nas camadas subjacentes. Vale-se, portanto de evidências diretas sobre o clima passado uma vez que as oscilações da temperatura na superfície se propagam lentamente no interior da crosta terrestre. As principais vantagens do método geotérmico em relação aos métodos tradicionais são:

1- Trata-se de um método direto onde as medidas de temperatura em profundidade são utilizadas para avaliar variações da temperatura no passado. Portanto, este método está livre das incertezas decorrentes da conversão dos indicadores indiretos em temperatura;

2- O período para o qual o método apresenta maior resolução compreende os últimos séculos abrangendo épocas anteriores às grandes mudanças da era industrial;

3- A condução de calor em subsuperfície integra as variações de temperatura continuamente ao longo dos dias e das estações do ano. Assim, os valores de temperatura medidos no subsolo representam uma média da temperatura da superfície. Ao contrário das estações meteorológicas que podem ser reposicionadas ou desativadas, o registro da temperatura no subsolo é contínuo; 
4- A existência de poços em regiões remotas permite o estudo das alterações climáticas em locais pouco perturbados pela ação do homem.

A metodologia adotada neste trabalho para a análise de perfis térmicos é constituída de três etapas:

$1^{\mathrm{a}}$ - Escolha do intervalo de profundidade onde os efeitos das perturbações climáticas estão ausentes. Os dados deste intervalo são utilizados para a determinação do gradiente geotérmico local.

$2^{a}$ - Eliminação do efeito do fluxo geotérmico na distribuição de temperaturas. Calcula-se para esta finalidade a temperatura residual, como a diferença entre a temperatura observada e aquela calculada com base no gradiente térmico local. A relação utilizada é:

$$
T_{R}(z)=T(z)-\left[T_{0}+g z\right]
$$

onde $z$ é a profundidade, $T_{0}$ é a temperatura na superfície e $g$ o gradiente térmico. O perfil residual referese ao efeito das variações climáticas.

$3^{a}$ - Análise comparativa de temperatura residual com as curvas teóricas do modelo de propagação em subsuperfície das perturbações térmicas. Para esta finalidade supomos que a variação climática possa ser representada por uma relação de potência em tempo (Lachenbruch and Marshall, 1986):

$$
v(0, t)=D\left(t / t^{*}\right)^{n / 2}
$$

onde $t^{*}$ é o tempo decorrido (ou seja, a idade da perturbação climática), $D$ a magnitude da perturbação na superfície e $n$ é um parâmetro que determina a forma de variação climática. Para a condição inicial de $v(z, t)=0$ a solução de $v$ no tempo $t=t^{*}$ é dada por (Carslaw e Jaeger, 1959):

$$
v(z)=D 2^{n} \Gamma(n / 2+1) i^{n} \text { erfc }\left(z / \sqrt{4 \alpha t^{*}}\right)
$$

onde $\Gamma$ é a função gama, $i^{n}$ erfc representa a enésima integral da função erro complementar e $\alpha$ a difusividade térmica do meio geológico. O processo de ajuste de curvas teóricas inclui simulações numéricas, a partir de suposições a respeito da forma como ocorreu a variação climática. Foram utilizados dois modelos de mudanças climáticas: variação abrupta $(n=0)$ e variação linear $(n=2)$.

As curvas teóricas referentes à solução acima foram ajustadas à perturbação observada no perfil geotérmico pelo método dos mínimos quadrados. Incluindo a temperatura na superfície e o gradiente térmico, o número total de parâmetros a serem ajustados para cada solução é quatro. São calculadas as somas dos desvios quadrados entre a temperatura residual e a temperatura calculada. O melhor ajuste corresponde ao menor valor da soma dos desvios.

Apresenta-se na figura (1) um exemplo do procedimento adotado nas etapas (1) e (2) da metodologia acima descrita, para o perfil térmico de um poço localizado no município de Jacareí (SP). Também são indicados nesta figura valores de gradiente térmico não perturbado (g) e a temperatura da superfície anterior ao aquecimento climático $\left(\mathrm{T}_{0}\right)$. O procedimento ajuste correspondente à terceira etapa da metodologia é ilustrado na figura (2). Nesta figura os pontos indicam os valores de temperaturas residuais enquanto as linhas contínuas referem-se as variações calculadas a partir do modelo teórico (equação - 3). Neste caso específico a curva que deu melhor ajuste (curva de cor azul) indica magnitude de variação climática de $2,5^{\circ} \mathrm{C}$. As curvas superior (cor rosa) e inferior (cor vermelho) referem-se aos valores previstos pelo modelo com magnitudes de $2^{0} \mathrm{C}$ e $3^{0} \mathrm{C}$ respectivamente.

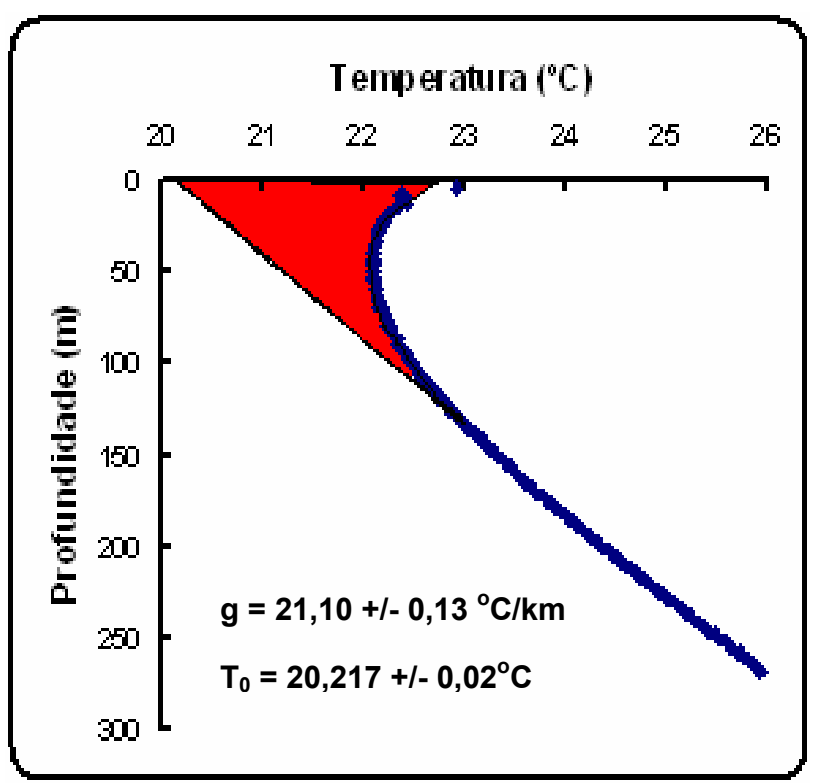

Figura (1) - Perfil térmico do poço em Jacareí (SP). Os pontos indicam temperaturas observadas. A área de cor

vermelha indica propagação em subsuperfície do aquecimento climático ocorrido nos últimos 145 anos.

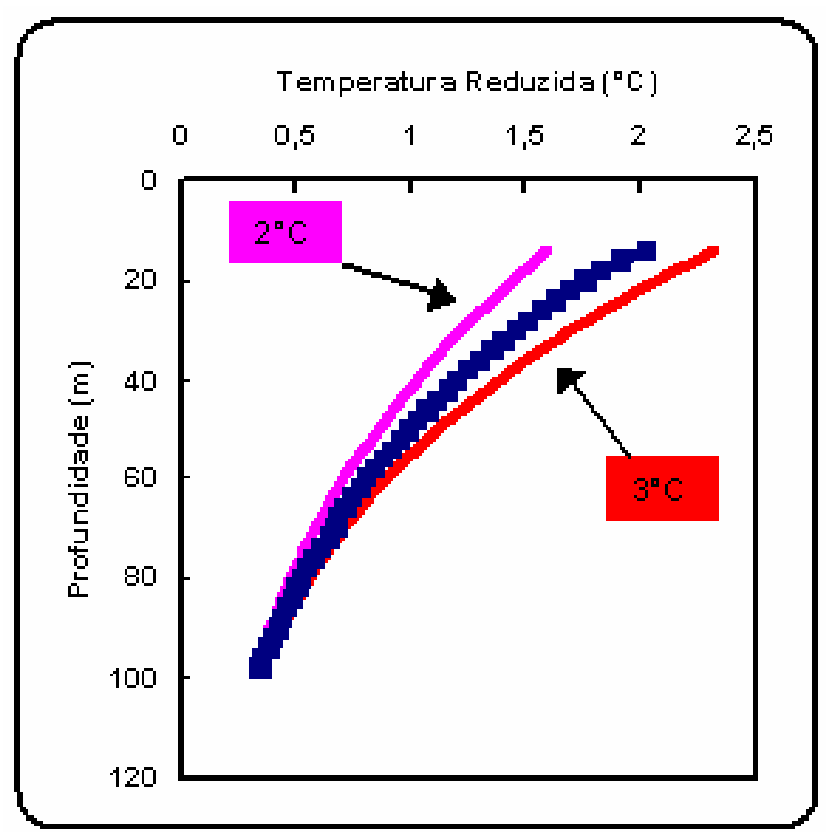

Figura (2) - Exemplo de ajuste de curvas teóricas aos valores de temperaturas reduzidas (pontos de cor azul) obtidos no poço em Jacareí (SP). 


\section{Resultados}

Os resultados dos ajustes do modelo linear aos dados observados são apresentados na tabela (1). Com exceção dos dados de Atibaia as magnitudes das mudanças climáticas estão no intervalo de $0,8^{\circ} \mathrm{C}$ a $3,8^{\circ} \mathrm{C}$. As idades das mudanças climáticas variam de 40 á 165 anos. Os resultados do modelo abrupto, apresentados na Tabela (2), indicam magnitudes semelhantes ao do modelo linear (faixa de $0,8^{\circ} \mathrm{C}$ a $3,2^{\circ} \mathrm{C}$ ). Contudo, as idades das mudanças climáticas são menores, na faixa de 20 a 94 anos.

Com base nos resultados de ajustes foram elaborados mapas, em escala regional, das variações climáticas no Estado do São Paulo. Apresenta-se na figura (3) resultados do modelo supondo que as variações climáticas ocorreram de forma linear. Na região leste do Estado o valor médio da variação climática é de $2,4^{\circ} \mathrm{C}$. $\mathrm{O}$ mapa indica que a magnitude de perturbação climática é maior na parte interior do Estado. Contudo, existe a possibilidade de que esta tendência é um artefato oriundo da distribuição não homogênea dos dados.

Resultados do modelo, supondo que as variações climáticas ocorreram de forma abrupta,as magnitudes das variações são menores, na faixa de $0,8^{\circ} \mathrm{C}$ a $3,2^{\circ} \mathrm{C}$.

As idades das variações climáticas determinadas pelo modelo linear estão no intervalo de 40 a 165 anos. O mapa da figura (5) que ilustra a distribuição geográfica deste parâmetro aponta para uma tendência de diminuição sistemática das idades de perturbação climática nas regiões interiores. Os resultados correspondentes para o modelo abrupto, apresentado na figura (6), indica que a tendência mantém-se a mesma, porém com idades menores, entre 20 e 94 anos. Estas conclusões também devem ser consideradas como provisórias, pois a ausência de dados na parte interior do estado dificulta a análise de tendências em escala regional. Dados geotérmicos apropriados da região oeste do Estado de São Paulo são necessários para análise detalhada destas tendências.

\section{Discussão e Conclusões}

Os resultados obtidos no presente trabalho permitiram o mapeamento das mudanças climáticas do último século, ocorridas na parte leste do Estado de São Paulo. Os resultados obtidos pelo modelo linear são considerados mais representativos da forma de variação climática. De acordo com este modelo a região leste do Estado é caracterizada por aquecimentos climáticos recentes com magnitudes de 0,8 a $3,8^{\circ} \mathrm{C}$. Há indícios de que as magnitudes das perturbações climáticas são menores na área costeira e maiores na região oeste. É possível que esta característica seja relacionada com a influencia do mar e a natureza das mudanças na cobertura vegetal.

As idades das variações climáticas se encontram no intervalo de 40 a 165 anos. Os mapas indicam tendências de idades menores na região oeste. É possível que os avanços nas práticas agrícolas e utilização do solo tenham contribuído para esta característica.

Há indícios de que as perturbações climáticas observadas possuam duas componentes: variações em escala global, causada pelo efeito estufa e variações induzidas em escala local, por mudanças de vegetação e uso do solo.

As idades das variações com valores acima de 100 anos coincide com o período de colonização em larga escala da área costeira do Estado. Sendo assim é possível que as mesmas idades estejam relacionadas com atividades antropogênicas.

\section{Agradecimentos}

O primeiro autor deste trabalho é recipiente de Bolsa de Iniciação Científica pelo programa PIBIC (CNPq).

\section{Referências}

Carslaw, H. S., Jaeger, J. C., 1959, Conduction of heat in solids. $2^{\text {nd }}$ ed. Clarendon Press, Oxford.

Cavalcanti, A.S.B., 2003, Variações paleoclimáticas no Brasil com base no método geotérmico., Dissertação de Mestrado, Observatório Nacional - ON/MCT, Rio de Janeiro.

Cavalcanti, A.S.B. e Hamza, V.M., 2001, Climate changes of the recent past in southern parts of Brazil (Extended Abstract), $7^{\text {th }}$ International Congress of the Brazilian Geophysical Society, Salvador (BA).

Cerrone, N.B. e Hamza, V.M., 2003, Variações paleoclimáticas no Estado do Rio de Janeiro, com base no método geotérmico (Resumo Expandido), $8^{0}$ International Congress of the Brazilian Geophysical Society, Rio de Janeiro (RJ).

Hamza, V. M.. 1991 Evidências geotérmicas sobre variações climáticas recentes no hemisfério sul. Anais do $2^{0}$ Congresso Brasileiro de Geofísica, Salvador (BA), 971-973.

Hamza, V.M., 1998, A proposal for continuous recording of subsurface temperatures at the sites of Geomagnetic field Observatories. Rev. Geofísica, Instituto Panamericano de Geografia e História v.48, 183-198.

Hamza, V. M.; Ribeiro, F. B.; Becker, E. A. 1991. Recent Climatic Changes in the Southern Hemisphere. $X X$ General Assembly, IUGG, Viena (Austria).

Hansen, J., and Lebedeff, X., 1987, Global trends of measured surface air temperatures. J. Geophys. Res., 92: 13345-13372.

Lanchenbruch, A. H., Sass, J. H., Marshall, B. V., 1986, Changing Climate: geothermal evidence from permafrost in the Alaskan Artic. Science, Vol. 234, No 7: 689-696. 
Tabela (1): Magnitude e idade dos sinais térmicos das mudanças climáticas no Estado de São Paulo, determinado com base no modelo de variação linear. $\Delta T$ - Magnitude, Idade (anos), e $\sigma$ a variância de ajuste.

\begin{tabular}{|c|c|c|c|c|}
\hline \multirow{2}{*}{ Local / Poço } & \multicolumn{4}{|c|}{ Mudança Climática } \\
\cline { 2 - 5 } & $\boldsymbol{\Delta} \mathbf{T}\left({ }^{\circ} \mathbf{C}\right)$ & Idade (anos) & $\begin{array}{c}\text { Ano do Início } \\
\text { da Perturbação }\end{array}$ & $\boldsymbol{\sigma}\left({ }^{\circ} \mathbf{C}\right)$ \\
\hline Águas de Lindóia-P01 & 3,2 & 105 & 1877 & 0,004 \\
\hline Amparo -P01 & 2,8 & 130 & 1852 & 0,005 \\
\hline Araras -P01 & 3,4 & 40 & 1942 & 0,006 \\
\hline Atibaia -P01 & 0,2 & 25 & 1957 & 0,004 \\
\hline Cosmópolis-P01 & 3,8 & 75 & 1907 & 0,009 \\
\hline Itapira -P01 & 1,2 & 40 & 1942 & 0,010 \\
\hline Itu -P01 & 1,2 & 60 & 1922 & 0,003 \\
\hline Jacareí-UFP15 & 2,5 & 145 & 1840 & 0,007 \\
\hline Jundiaí-P01 & 1,2 & 50 & 1932 & 0,007 \\
\hline Lindóia -P01 & 0,8 & 105 & 1877 & 0,007 \\
\hline Rafard -P01 & 3,8 & 60 & 1922 & 0,006 \\
\hline Serra Negra -P01 & 2,0 & 105 & 1877 & 0,003 \\
\hline Serra Negra -P02 & 2,8 & 60 & 1922 & 0,003 \\
\hline Serra Negra -P03 & 2,2 & 45 & 1937 & 0,010 \\
\hline São Sebastião- SR9 & 2,7 & 165 & 1826 & 0,010 \\
\hline
\end{tabular}

Tabela (2) Magnitude e idade dos sinais térmicos das mudanças climáticas no Estado de São Paulo, determinado com base no modelo de variação abrupta. $\Delta T$ - Magnitude, Idade (anos), e $\sigma$ a variância de ajuste.

\begin{tabular}{|c|c|c|c|c|}
\hline \multirow{2}{*}{ Local / Poço } & \multicolumn{4}{|c|}{ Mudança Climática } \\
\cline { 2 - 5 } & $\boldsymbol{\Delta} \mathbf{T}\left({ }^{\circ} \mathbf{C}\right)$ & Idade (anos) & $\begin{array}{c}\text { Ano do Início } \\
\text { da Perturbação }\end{array}$ & $\boldsymbol{\sigma}\left({ }^{\circ} \mathbf{C}\right)$ \\
\hline Águas de Lindóia-P01 & 2,4 & 65 & 1917 & 0,003 \\
\hline Amparo -P01 & 2,4 & 70 & 1912 & 0,003 \\
\hline Araras -P01 & 2,2 & 30 & 1952 & 0,009 \\
\hline Atibaia -P01 & 0,2 & 20 & 1962 & 0,005 \\
\hline Cosmópolis-P01 & 3,0 & 45 & 1937 & 0,009 \\
\hline Itapira -P01 & 2,6 & 35 & 1947 & 0,020 \\
\hline Itu -P01 & 0,8 & 50 & 1932 & 0,006 \\
\hline Jacareí-UFP15 & 2,2 & 51 & 1934 & 0,020 \\
\hline Jundiaí-P01 & 0,8 & 45 & 1937 & 0,010 \\
\hline Lindóia -P01 & 0,6 & 80 & 1902 & 0,003 \\
\hline Rafard -P01 & 3,2 & 38 & 1947 & 0,010 \\
\hline Serra Negra -P01 & 1,6 & 65 & 1917 & 0,003 \\
\hline Serra Negra -P02 & 2,2 & 38 & 1947 & 0,004 \\
\hline Serra Negra -P03 & 1,8 & 30 & 1952 & 0,001 \\
\hline São Sebastião- SR9 & 2,2 & 94 & 1897 & 0,010 \\
\hline
\end{tabular}




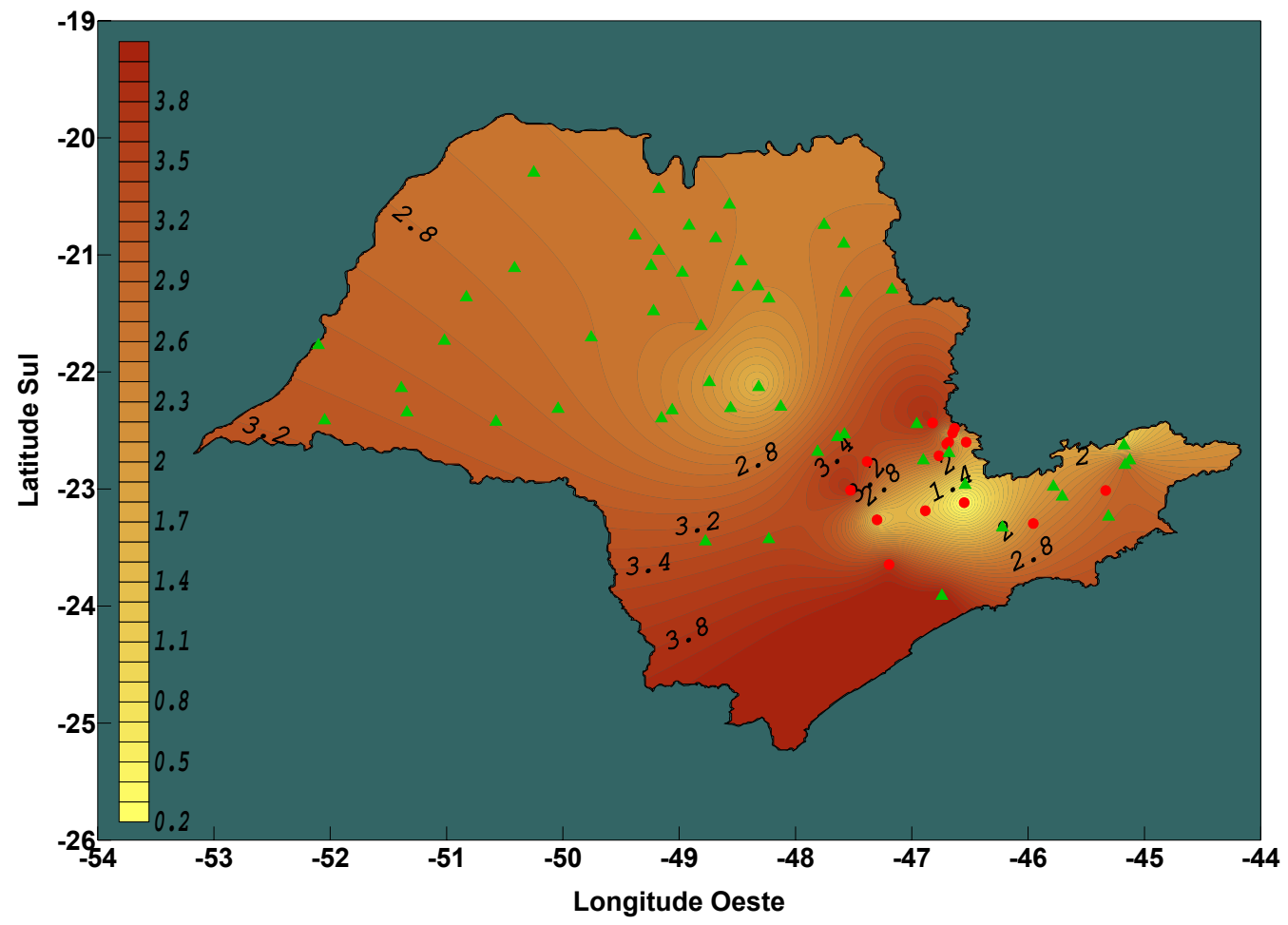

Figura (3) - Magnitude da perturbação climática inferida a partir de modelo de variação linear. Os círculos indicam locais de perfis geotérmicos analisados no presente trabalho. Os triângulos indicam os demais locais de medições geotérmicas que ainda não foram analisadas. As curvas de isovalores estão em unidades de graus centígrados.

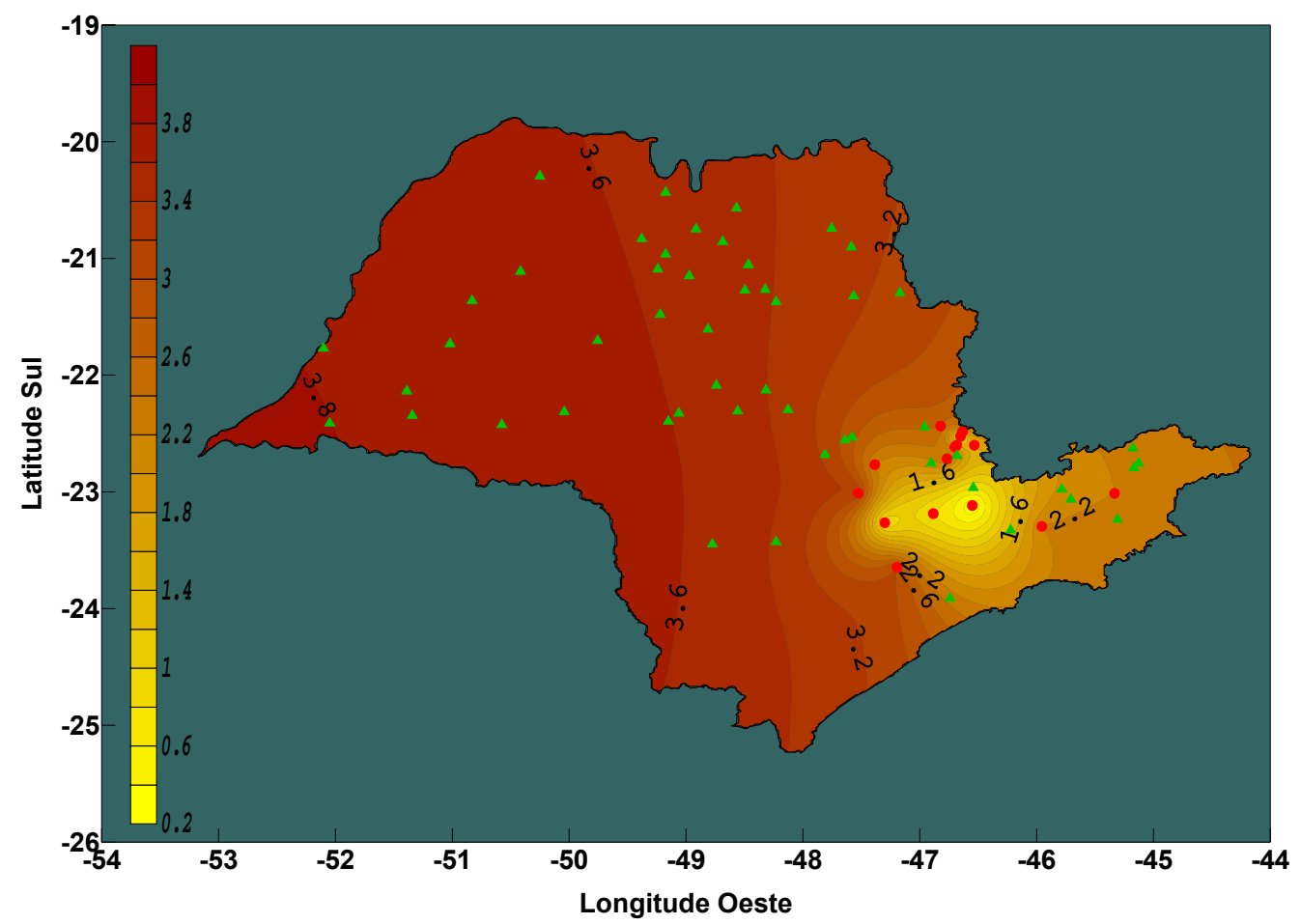

Figura (4) - Magnitude da perturbação climática inferida a partir de modelo de variação abrupta. Os círculos indicam locais de perfis geotérmicos analisados no presente trabalho. Os triângulos indicam os demais locais de medições geotérmicas que ainda não foram analisadas. As curvas de isovalores estão em unidades de graus centígrados. 


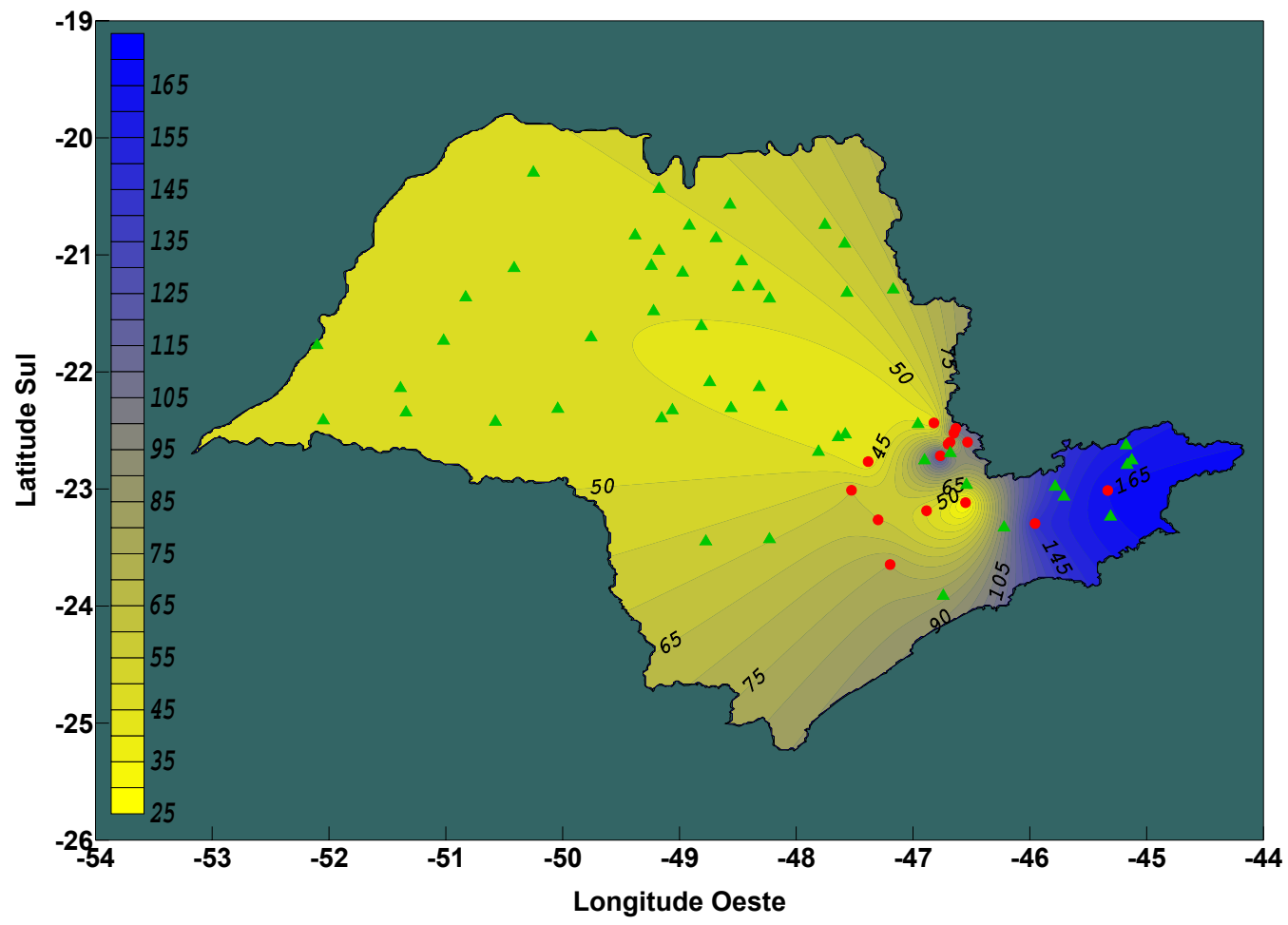

Figura (5) - Idade da perturbação climática inferida a partir do modelo de mudança linear. Os círculos indicam locais de perfis geotérmicos analisados no presente trabalho. Os triângulos indicam os demais locais de medições geotérmicas que ainda não foram analisadas. As curvas de isovalores estão em unidades de anos.

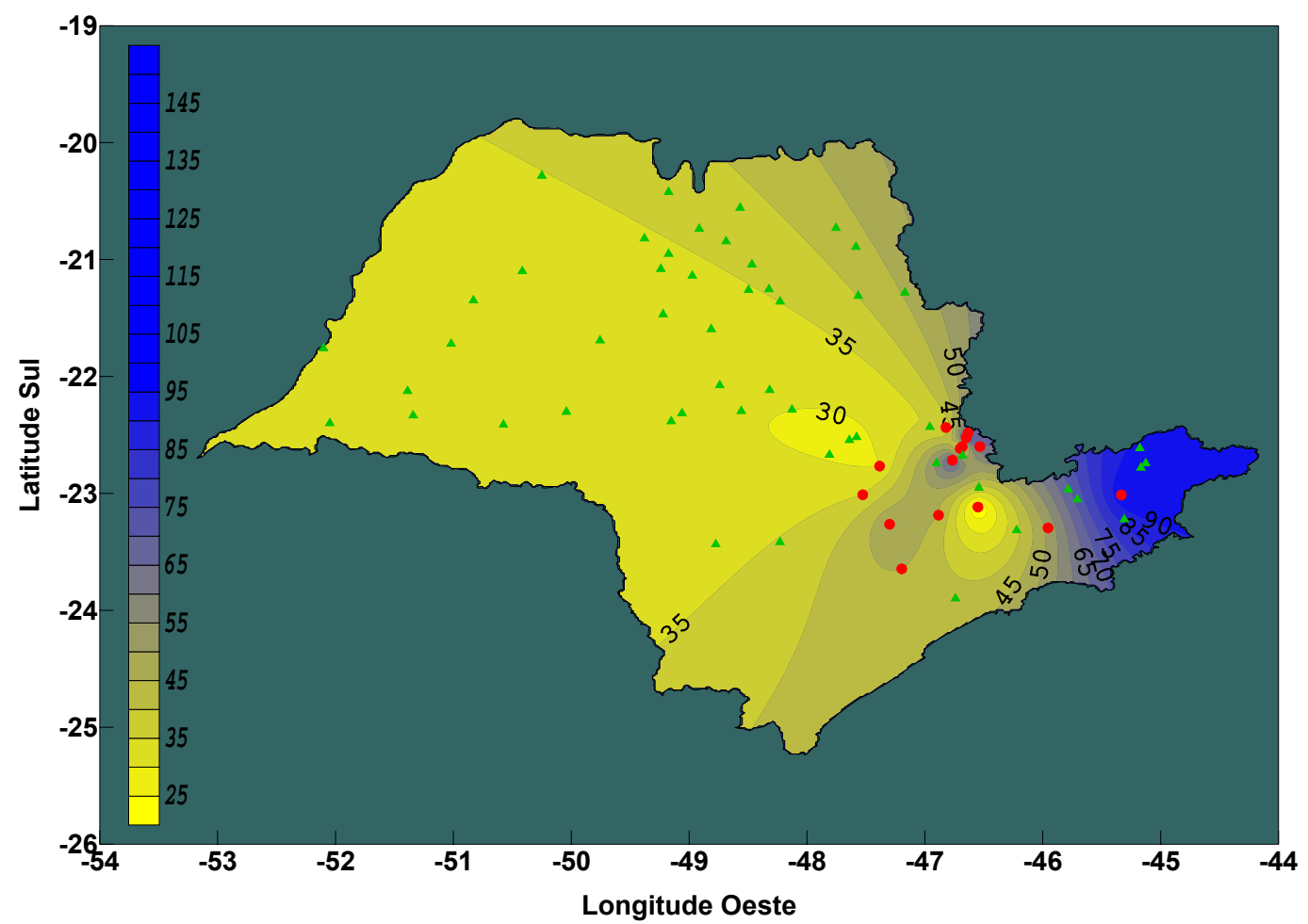

Figura (6) - Idade da perturbação climática inferida a partir do modelo de mudança abrupta. Os círculos indicam locais de perfis geotérmicos analisados no presente trabalho. Os triângulos indicam os demais locais de medições geotérmicas que ainda não foram analisadas. As curvas de isovalores estão em unidades de anos. 